\title{
ESTUDO DA DISPOSIÇÃO FINAL DE RESÍDUOS SÓLIDOS DE CURTUME COMO FONTE DE ALTERAÇÃO DA QUALIDADE DAS ÁGUAS SUBTERRÂNEAS
}

\author{
ASSESSMENT OF THE FINAL DISPOSAL OF SOLID RESIDUES FROM TANNERIE \\ AS A SOURCE OF ALTERATION OF GROUNDWATER QUALITY
}

\author{
Renato Blat Migliorini ${ }^{1}$, Eliana Freire Gaspar de Carvalho Dores ${ }^{2}$ e Edinaldo de Castro e Silva ${ }^{2}$
}

Recebido em 25/01/2006; Aceito em: 04/10/2006

\begin{abstract}
RESUMO Este trabalho tem por objetivo estudar os impactos causados nas águas subterrâneas pela disposição de resíduos gerados por dois curtumes localizados nos municípios de Cuiabá e Várzea Grande, no estado de Mato Grosso. Em um dos curtumes (curtume 1), a disposição final dos resíduos era feita sobre uma manta impermeável instalada dentro da trincheira, com cobertura de telhas de amianto; enquanto no outro (curtume 2), os resíduos foram dispostos diretamente no solo da trincheira e cobertos com a manta impermeável. Foram investigados parâmetros indicadores de alteração físicoquímica e química das águas subterrâneas nas áreas de disposição final dos resíduos gerados por esses curtumes. As amostras de águas subterrâneas foram obtidas por meio de poços de monitoramento construídos nesses locais. Os resultados das análises físico-químicas, dos elementos metálicos e não metálicos permitiram as seguintes conclusões: i) a presença dos resíduos gerados pelo curtume 1 , contribuiu para elevar os teores de cromo, $\mathrm{pH}$, condutividade elétrica e, portanto, também sólidos totais dissolvidos; ii) a presença dos resíduos gerados pelo curtume 2, contribuiu para elevar os teores de cloreto, condutividade elétrica e, por conseqüência, de sólidos totais dissolvidos e iii) embora os dois curtumes estejam em funcionamento por períodos diferentes (curtume 1 foi implantado em 2.000 e o curtume 2 em 1986) e usando métodos diferentes de disposição dos rejeitos, não se observou diferenças significativas nas alterações da qualidade das águas subterrâneas nos dois locais.
\end{abstract}

Palavras-Chave: água subterrânea, resíduos de curtume, qualidade da água.

\begin{abstract}
This work aim to study the impacts caused by the disposal of residues from two tanneries localized in the municipalities of Cuiabá and Várzea Grande in Mato Grosso State, particularly on groundwater. In one of the tanneries (tannery 1), the final residue disposal was done over an impermeable blanket inside a trench covered with amianthus tiles while in the other (tannery 2) the residues were disposed directly on the soil covered with the impermeable blanket. To achieve this objective, physical chemical and chemical properties which could indicate alteration of groundwater quality in the areas of final disposal of tannery residues were determined. Groundwater samples were collected in monitoring wells built in those areas. The analysis of the physical chemical and chemical variables allowed the following conclusions: i) the residues disposal in tannery 1 contributed to increase chromium concentrations, $\mathrm{pH}$; electrical conductivity and also total dissolved solids; ii) the residues disposal in tannery 2, contributed to increase the concentrations of chloride, electrical conductivity and as a consequence total dissolved solids. Although the two tanneries are at work for different times (tannery 1 from 2000 and tannery 2 from 1986) using different residues disposal procedures, no significant difference were observed in the alteration of groundwater quality in the two sites.
\end{abstract}

Keywords: groundwater, tannery residue, water quality

\section{INTRODUÇÃO}

$\mathrm{O}$ acelerado processo de industrialização observado em algumas regiões do país, aliado à expansão demográfica dele decorrente, vem acarretando aumento considerável na produção de resíduos, particularmente dos de origem industrial. A indústria pode ser fonte de alguns dos mais sérios problemas ambientais, especialmente daqueles relacionados à poluição do ar, água e solo. Esses problemas podem ter impactos imediatos à saúde humana.

$\mathrm{Na}$ região Centro-Oeste, a partir da década de 70, com a nova dinâmica dada à economia, a atividade industrial ganhou novo impulso. O estado de Mato Grosso está vivendo um momento de grande expansão, principalmente na agroindústria, com destaque para o setor de frigorífico que conta atualmente com 22 estabelecimentos, abatendo cerca de 13.000 cabeças/dia de gado bovino (IBGE, 2007). Com isso gera grande quantidade da matéria-prima couro, que é produto básico na indústria de curtimento.

A indústria de curtimento caracteriza-se pelo alto poder de poluição causado pelos efluentes gerados no processamento da pele e pela disposição inadequada de resíduos líquidos e sólidos sobre corpos de águas e solos que degradam a qualidade do meio ambiente.

\section{OBJETIVO}

Pretende-se com este trabalho estudar os impactos causados nas águas subterrâneas pela disposição dos resíduos gerados por dois curtumes

\footnotetext{
${ }^{1}$ Departamento de Geologia Geral - Universidade Federal de Mato Grosso (rena@ufmt.br)

22Departamento de Química - Universidade Federal de Mato Grosso (eliana @ufmt.br) (edinaldo@ufmt.br)
} 
localizados nos municípios de Cuiabá e Várzea Grande, no estado de Mato Grosso. Para isso, foram investigados parâmetros indicadores de alteração físico-química e química das águas subterrâneas nas áreas de disposição final dos resíduos gerados por estes curtumes.

\section{RESÍDUOS EM INDÚSTRIAS DE CURTIMENTO}

No processo produtivo do curtume, que consiste em transformar a pele do animal em couro, as mesmas são submetidas à ação de diferentes agentes químicos que interagem com as fibras para a obtenção de um couro estável e durável. Os agentes químicos utilizados são: sal para conservação da pele; água para retirar o sal; repor o teor de água das peles utilizando sais, álcalis, ácidos e enzimas; para remoção dos pelos e o sistema epidérmico é utilizado cal e sulfeto de sódio; para remover as substâncias alcalinas são utilizados amoniacais, bissulfito de sódio ou ácidos fracos; para limpeza da estrutura fibrosa são utilizadas enzimas; para preparar as fibras colágenas para receber os agentes curtentes é utilizado um processo salino ácido; para o curtimento que é o processo que transforma a pele em couro é utilizado o cromo; para eliminar os ácidos livres existentes no couro é utilizado um processo de neutralização (RIBEIRO NETO, 1982).

Grande parte do resíduo de curtume (lodo) é constituída de matéria orgânica de origem animal misturada com sais inorgânicos. Alguns desses componentes são nutrientes para as plantas, como nitrogênio, fósforo, potássio, enxofre, cálcio e magnésio (SELBACH et al., 1991).

O nitrogênio é o macronutriente encontrado em maior quantidade no resíduo de curtume, devido à natureza protéica de grande parte de seus constituintes. Pela decomposição microbiana dos resíduos no solo, ocorre a transformação rápida do $\mathrm{N}$ protéico em amônia, que pode ser absorvida pelas plantas e/ou ser nitrificado pela ação das bactérias Nitrosonomas $s p$. e Nitrobacter sp (SELBACH et al; 1991).

O lodo, considerado seco, contém mais de cinqüenta por cento de água, possui compostos orgânicos (dissolvidos e suspensos), compostos orgânicos tóxicos, agentes patogênicos, metais, nutrientes, nitrogênio, fósforo e potássio, entre outros (CLAAS, 1994).

Os lodos produzidos pelo Sistema de Tratamento de Efluentes de um curtume são os que apresentam maiores problemas de disposição final. Apesar de várias soluções tecnológicas terem sido propostas para a reutilização desses materiais, até o momento, não existem soluções em larga escala para o problema. A solução mais utilizada universalmente é o aterro industrial. Entre as soluções alternativas, a mais conhecida é a utilização desses resíduos na agricultura como fertilizante. Também é utilizado (em menor escala) na produção de tijolos, sendo que, a alternativa de uso na agricultura, demonstrou ser viável em nível experimental (JOST, 1989).

É interessante citar dois trabalhos realizados na Índia que estudam contaminação das águas subterrâneas por resíduos de curtume (MONDAL et al., 2005 e ZAHID et al., 2006). Aqui no estado de Mato Grosso podemos citar Lannes (2002); Vogado; Migliorini (2005 e 2006); Costa; Migliorini (2005), Cunha (2005) e Fachin et al. (2006), estudaram as águas subterrâneas no entorno das trincheiras de deposição de resíduos de tratamento de curtume, localizados nos municípios de Cuiabá e Várzea Grande/MT. Todos os trabalhos citados tanto na Índia quanto em Mato Grosso concluíram que houve alteração das águas subterrâneas através da variação da concentração dos constituintes físicos, químicos e alguns elementos traços.

\section{GEOLOGIA LOCAL}

O Grupo Cuiabá na região estudada expõese sob a forma de uma anticlinal invertida com caimento para $\mathrm{NE}$, definindo uma estruturação onde os contatos entre os diversos litotipos, as foliações plano-axiais ao dobramento e as falhas relacionadas às dobras, desenham uma orientação preferencialmente $\mathrm{N} 30^{\circ}-40^{\circ} \mathrm{E}$. A seguir são citadas as litofácies ou conjuntos litológicos, que correspondem o Grupo Cuiabá (MIGLIORINI, 1999).

\section{Formação Miguel Sutil}

Esta unidade, que corresponde à Subunidade 5 do Projeto Coxipó (LUZ et al., 1980), aflora praticamente em toda a porção central e norte das cidades de Cuiabá e Várzea Grande, mais precisamente, no núcleo da anticlinal invertida que descreve o arcabouço estrutural desta região.

São individualizados dois conjuntos faciológicos para esta formação: Litofácies argilo-areno-conglomerático e Litofácies pelítica com laminação plano-paralela (MIGLIORINI, 1999). 


\section{Formação Rio Coxipó}

Esta unidade, que corresponde à Subunidade 6 de Luz et al. (1980), sobrepõe-se à Formação Miguel Sutil através de contatos transicionais e tectônicos e aflora, principalmente, na porção sul das cidades de Cuiabá e Várzea Grande. Sob o ponto de vista do arranjo estrutural local, a sua exposição restringe-se ao flanco invertido da dobra anticlinal invertida com caimento para NE (MIGLIORINI, 1999).

São individualizadas duas associações litológicas principais: a dos metadiamictitos com matriz argilosa, maciços, com raras intercalações de areia fina a média e dos metadiamictitos, com matriz arenosa, intercalados a arenitos quartzosos grossos e médios (MIGLIORINI, 1999).

\section{Geologia na região dos curtumes}

O curtume $n^{\circ} 1$, em Cuiabá, está inserido geologicamente na Litofácies pelítica com laminação plano-paralela da Formação Miguel Sutil.

O curtume $\mathrm{n}^{\mathrm{o}}$ 2, em Várzea Grande, está inserido geologicamente na Litofácies metadiamectito de matriz argilosa da Formação Rio Coxipó.

\section{HIDROGEOLOGIA LOCAL}

As zonas aqüíferas na região de Cuiabá e Várzea Grande são do tipo livre, heterogêneas e anisotrópicas, com intensa variação lateral e em profundidade. A matriz do corpo rochoso é caracterizada pela inexistência e/ou presença reduzida de espaços intergranulares. A água subterrânea encontra-se, preferencialmente, nas descontinuidades das rochas, como fraturas, fissuras, diáclases e outras, isto é, nas porosidades secundárias. A trama e intensidade destas descontinuidades definem o potencial do aquiífero (MIGLIORINI, 1999).

$\mathrm{Na}$ região estudada encontram-se dois sistemas aquiíferos: um poroso (no manto de alteração) e outro no meio fraturado (nas rochas). Pode-se separar dois domínios hidrogeológicos no meio fraturado. Um é o domínio da Formação Miguel Sutil, que ocupa praticamente toda a porção central e norte das cidades de Cuiabá e Várzea Grande. O outro domínio é o da Formação Rio Coxipó, que ocupa principalmente a porção sul da região. No primeiro domínio, a litofácies argilo-arenoconglomerática apresenta as melhores condições aquíferas e, no segundo domínio, os metadiamictitos com matriz arenosa apresentam as melhores condições aqüíferas (MIGLIORINI, 1999).

A produtividade das zonas aquiúferas dependerá das características do manto de alteração e do grau de fraturamento das rochas. As melhores situações são aquelas com um manto de alteração predominantemente arenoso, com grande espessura, sobrepostas a rochas com elevado grau de fraturamento. Também poderão ser encontradas situações intermediárias e em diferentes proporções (MIGLIORINI, 1999).

As águas do aquiífero freático na região estudada apresentam grau de vulnerabilidade geralmente alta à poluição. $\mathrm{O}$ manto de alteração aliado às fraturas das rochas apresentam-se normalmente vulneráveis à infiltração de poluentes, principalmente por coliformes. Nas áreas onde a espessura da zona não saturada é maior, o aqüífero tem maior poder de autodepuração e nas áreas onde o nível da água é raso, a vulnerabilidade à contaminação aumenta (MIGLIORINI, 1999).

\section{METODOLOGIA}

A primeira etapa do trabalho foi escolher dois curtumes na região metropolitana de Cuiabá e Várzea Grande no Estado de Mato Grosso.

O primeiro curtume escolhido (curtume 1) que está localizado na cidade de Cuiabá, foi implantado no ano 2000. Observa-se na Figura 1 duas trincheiras em forma de L, onde são dispostos os resíduos do curtume. 


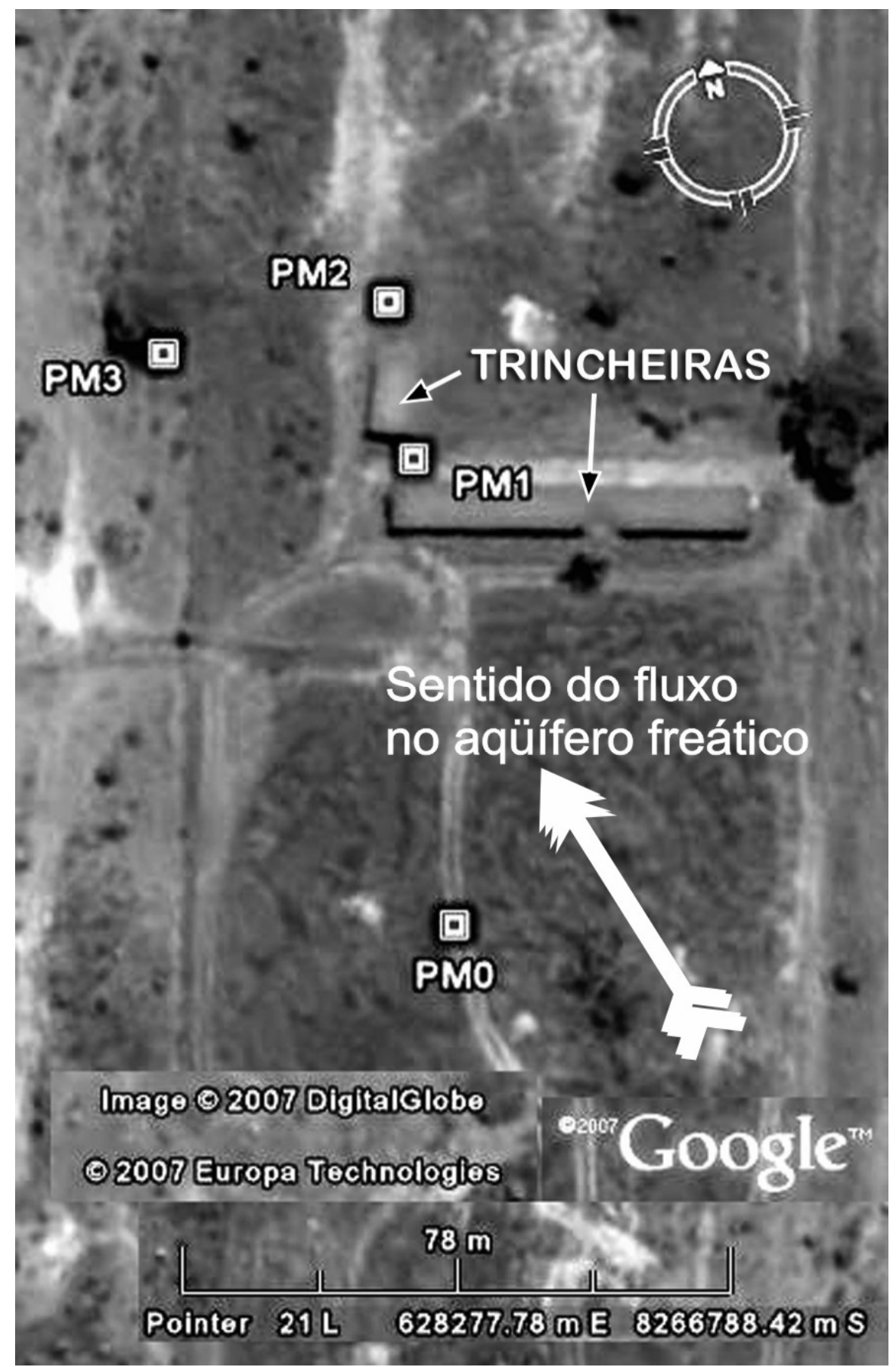

Figura 1 - Imagem do Curtume 1 com localização das trincheiras, localização dos poços de monitoramento (PM) e direção e sentido do fluxo das águas subterrâneas. (Fonte: imagem Google Earth acessado em 10/10/2007). Figure 1 - Image of tannery 1 and localization of disposal trenchs, monitoring wells (PM) and direction and orientation of groundwater flow. (Source: image of Google Earth accessed on 10 Oct 2007). 


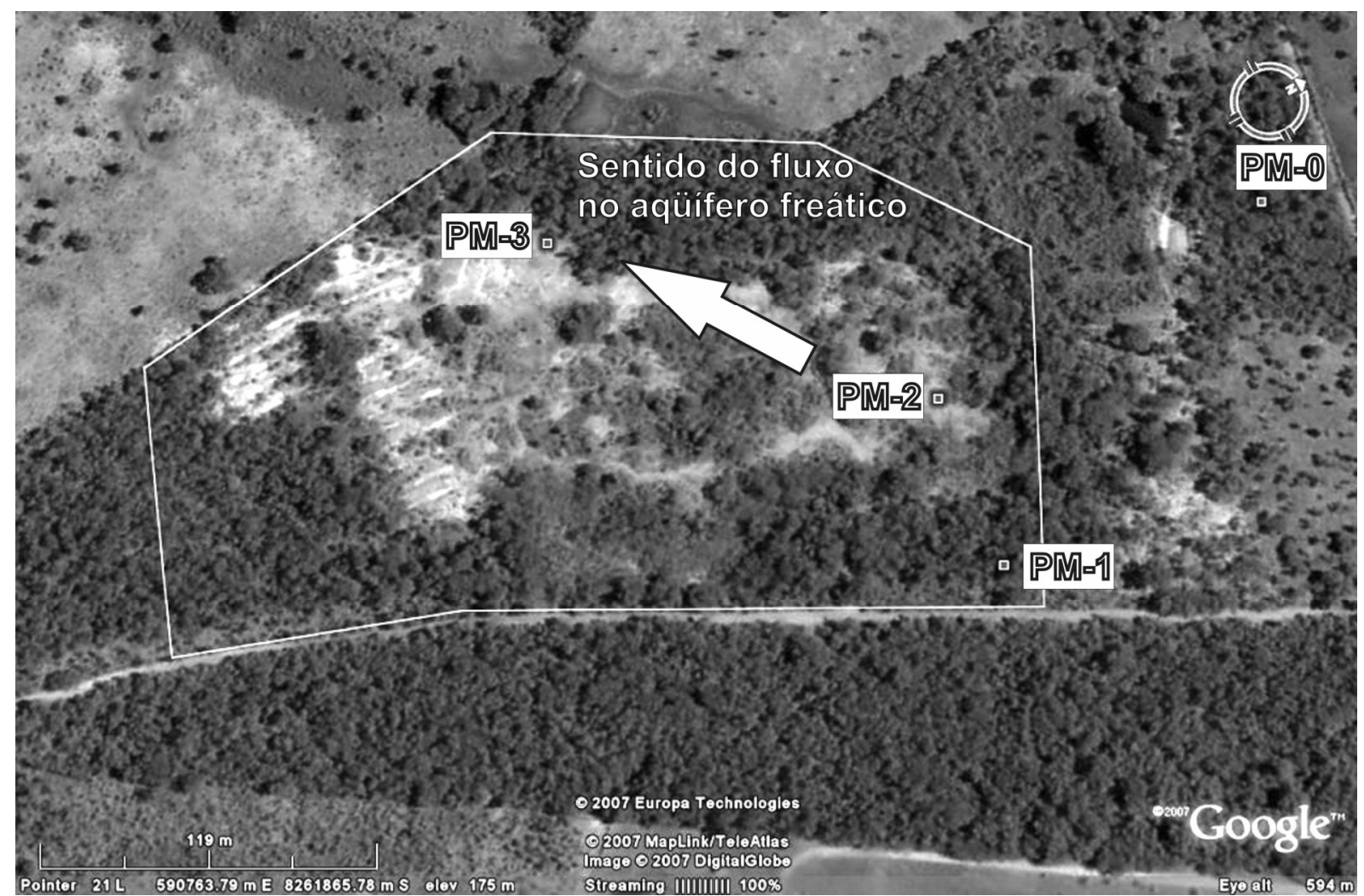

Figura 2 - Imagem do Curtume 2 com localização das trincheiras (no interior do polígono), localização dos poços de monitoramento (PM) e direção e sentido do fluxo das águas subterrâneas (Fonte: imagem Google Earth acessado em 10/10/2007).

Figure 2 - Image of tannery 1 and localization of disposal trenchs, monitoring wells (PM) and direction and orientation of groundwater flow. (Source: image of Google Earth accessed on 10 Oct 2007).

A segunda etapa foi a construção de quatro poços de monitoramento no Curtume 1 e quatro poços de monitoramento no Curtume 2, localizados no entorno das trincheiras de disposição final dos resíduos, em locais previamente orientados por estudos geofísicos. Foram utilizados os métodos geofísicos: Eletromagnético Indutivo (EM-34) e Caminhamento Elétrico (sondagem elétrica vertical pelo método da eletrorresistividade), através dos quais foi determinada a profundidade do nível d' água e delimitada a pluma de contaminação, que auxiliou na locação dos poços de monitoramento (CUNHA, 2005 e FACHIN et al; 2006).

Os furos para construção dos poços de monitoramento foram executados com trado mecânico de 4" de diâmetro. Os poços foram construídos com tubos de PVC com diâmetro de 3 " e com ranhuras de aproximadamente $2 \mathrm{~mm}$ no último metro (seção filtrante). A seção filtrante foi envolta com tela de material inerte (nylon) para diminuir a infiltração de sedimentos. A extremidade inferior do tubo de PVC foi fechada com tampa de PVC rosqueada evitando o uso de cola, que poderia alterar a composição química da água. $\mathrm{O}$ espaço anelar entre o tubo de PVC e o furo foi preenchido com areia até $50 \mathrm{~cm}$ acima da seção filtrante, a qual faz o papel de pré-filtro. Acima da areia introduziu-se bentonita para impedir a infiltração de águas superficiais. Acima da bentonita foi introduzido o próprio material retirado do furo. Por fim, foram feitos selos sanitários de concreto na superfície em volta da boca do poço.

Com a finalidade de concluir com segurança se as alterações observadas eram ou não, devidas à presença dos curtumes, foi construído um poço de monitoramento em cada curtume, denominado (PM0) e localizado à montante dos depósitos de resíduos sólidos, servindo de controle (valores de background). Podem ser observadas nas Figuras 1 e 2 a localização dos poços de background (PM0) e a direção e sentido do fluxo das águas subterrâneas do aqüífero freático.

Para avaliar a influência da disposição dos rejeitos dos curtumes na qualidade da água subterrânea, usou-se o teste não-paramétrico de comparação estatística de grupos de dados de 
Kruskal-Wallis, entre os poços de monitoramento (PM1, PM2 e PM3) e o poço de background (PM0).

Com os poços de monitoramento construídos, foi iniciado o monitoramento propriamente dito. No período da manhã, era medido o nível da água e os poços de monitoramento eram esgotados, para que a amostra de água fosse representativa. No período da tarde, era realizada a coleta de amostras para análises in situ e em laboratório.

A coleta abrangeu um ano hidrológico, isto é, com início no período de chuva ao período de chuva do ano seguinte (25/03/04, 05/05/04, $28 / 07 / 04, \quad 24 / 08 / 04, \quad 21 / 09 / 04, \quad 24 / 11 / 04$, 22/12/04, 28/01/05, 02/03/05 e 18/04/05).

Tomou-se cuidado para não transferir a contaminação de um poço de monitoramento para outro. Desta maneira, após cada amostragem, o coletor de água era trocado. Além do uso de luvas, evitou-se que o equipamento de coleta entrasse em contato com o solo.

Durante o processo de monitoramento, tomou-se cuidado com a preservação, armazenamento e transporte das amostras de água, a fim de não provocar alterações na qualidade físico-química das mesmas. Também, com o intuito de preservar as amostras de ação biológica, hidrólise, volatização e adsorção, as mesmas foram protegidas contra a luz e preservadas sob refrigeração em caixa de isopor com gelo (temperatura de $4^{\circ} \mathrm{C}$ ).

Foram coletadas amostras em frascos descartáveis de polietileno de um litro. Os frascos foram lavados previamente com ácido clorídrico $(0,1 \mathrm{~N})$, água destilada e com a própria água coletada.

Tomou-se cuidado para não deixar espaço vazio no frasco, a fim de evitar a possibilidade de volatização.

Nos frascos de polietileno foram anotados os locais, identificação do projeto, o número do poço de monitoramento, a data da coleta e identificação dos parâmetros a serem analisados no laboratório.

Foram determinados in situ a temperatura da água e do ar, $\mathrm{pH}$, condutividade elétrica e o nível da água.
As análises físico-químicas e químicas foram realizadas no Laboratório de Análise Metais Pesados do Departamento de Química do Instituto de Ciências Exatas e da Terra da Universidade Federal de Mato Grosso.

Além das variáveis determinadas em campo foram realizadas as seguintes análises: turbidez, sólidos totais dissolvidos, cromo, cobre, chumbo, ferro, zinco, cádmio, manganês, nitrito, nitrato, cloreto, alcalinidade, amônia, fósforo total e sulfato.

Para medir o $\mathrm{pH}$ foi empregado o método eletrométrico e o equipamento utilizado foi o pH-metro portátil, QUIMIS Q-400H. Para medir a turbidez foi utilizado o turbidímetro turbity/trübung, PC compact da AQUALYTIC. As temperaturas do ar e da água foram medidas com termômetro de contato, com limite de detecção 0,5. O equipamento utilizado foi termômetro com coluna de $\mathrm{Hg}$, certificado, escala de 0 a $100^{\circ} \mathrm{C}$, com variação de $0,1^{\circ} \mathrm{C}$. A condutividade elétrica foi determinada pelo método do eletrodo de platina e o equipamento utilizado foi o condutivímetro portátil Q-405P da QUIMIS. Os sólidos totais dissolvidos (STD), foram calculados pela equação STD = 0,65 x CE, segundo MATTHES (1982), onde CE é a condutividade elétrica medida no campo. A análise dos metais: cromo, cobre, chumbo, prata, ferro, zinco, cádmio e manganês, foi realizada por Espectrofotometria de Absorção Atômica e usado um espectrofotômetro SpectrAA 220 da Varian. A análise dos elementos nitrato, nitrito, amônia, alcalinidade, cloreto, fósforo total e sulfato foram realizados por Gravimetria e Espectrofotometria UV/Vis e o equipamento foi um espectrofotômetro ultravioleta da marca CELM, modelo E225. Todas as análises e métodos de coletas foram realizados segundo as normas do "Standard Methods for the Examination of Water and Wastewater" (1998).

\section{RESULTADOS E DISCUSSÃO}

Os resultados das análises físico-químicas, elementos metálicos e não metálicos, em termos estatísticos, estão apresentados nas tabelas 1 e 2 . 
Tabela 1 - Estatística descritiva dos dados físico-químicos, elementos metálicos e não metálicos da qualidade da água subterrânea no Curtume 1.

Table 1 -Descriptive statistics of physical chemical, metallic and non-metallic variables of groundwater quality in tannery 1

\begin{tabular}{c|c|c|c|c|c|c|c|}
\multicolumn{6}{c}{ Table I - Descriptive statistics of physical chemical, metallic and non-metallic variables of groundwater quality in tannery I } \\
\hline Parâmetros & Unidades & $\begin{array}{c}\text { Número de } \\
\text { Amostras }\end{array}$ & Média & $\begin{array}{c}\text { Desvio } \\
\text { Padrão }\end{array}$ & Mediana & Máximo & Mínimo \\
\hline Temperatura & ${ }^{\circ} \mathrm{C}$ & 40 & 28,8 & 1,5 & 28,9 & 31,5 & 26,1 \\
\hline $\mathrm{pH}$ & & 40 & 5,4 & 0,57 & 5,4 & 6,83 & 4,2 \\
\hline Alcalinidade & $\mathrm{mg} / \mathrm{L}$ & 36 & 117 & 468,6 & 17 & 2830 & 0 \\
\hline C.E. & $\mu \mathrm{S} / \mathrm{cm}$ & 40 & 534 & 716 & 289 & 3340 & 27,7 \\
\hline STD & $\mathrm{mg} / \mathrm{L}$ & 35 & 345 & 483 & 160 & 2171 & 18 \\
\hline Turbidez & $\mathrm{NTU}$ & 30 & 214 & 411 & 37 & 1485 & 1,4 \\
\hline Nitrito & $\mathrm{mg} / \mathrm{L}$ & 36 & 0,028 & 0,04 & 0,005 & 0,186 & 0,005 \\
\hline Nitrato & $\mathrm{mg} / \mathrm{L}$ & 36 & 0,14 & 0,3 & 0,05 & 1,44 & 0,02 \\
\hline Amônia & $\mathrm{mg} / \mathrm{L}$ & 36 & 1,028 & 2,4 & 0,14 & 10,15 & 0,01 \\
\hline Fósforo & $\mathrm{mg} / \mathrm{L}$ & 36 & 0,2 & 0,25 & 0,1 & 0,99 & 0,02 \\
\hline Cloreto & $\mathrm{mg} / \mathrm{L}$ & 35 & 210,3 & 397,1 & 58,2 & 1531 & 1,5 \\
\hline Sulfato & $\mathrm{mg} / \mathrm{L}$ & 36 & 4,0 & 10,2 & 0,2 & 40,6 & 0,1 \\
\hline Cromo & $\mathrm{mg} / \mathrm{L}$ & 40 & 0,3 & 0,3 & 0,2 & 1,92 & 0,2 \\
\hline Cobre & $\mathrm{mg} / \mathrm{L}$ & 40 & 0,03 & 0,015 & 0,02 & 0,09 & 0,02 \\
\hline Chumbo & $\mathrm{mg} / \mathrm{L}$ & 40 & 0,5 & 0,017 & 0,5 & 0,61 & 0,5 \\
\hline Ferro & $\mathrm{mg} / \mathrm{L}$ & 40 & 1,6 & 2,7 & 0,27 & 14,43 & 0,17 \\
\hline Zinco & $\mathrm{mg} / \mathrm{L}$ & 40 & 0,09 & 0,08 & 0,05 & 0,38 & 0,05 \\
\hline Cadmio & $\mathrm{mg} / \mathrm{L}$ & 40 & 0,01 & 0,005 & 0,01 & 0,03 & 0,01 \\
\hline Manganês & $\mathrm{mg} / \mathrm{L}$ & 40 & 0,73 & 1,0 & 0,29 & 4,62 & 0,1 \\
\hline
\end{tabular}

Tabela 2 - Estatística descritiva dos dados físico-químicos, elementos metálicos e não metálicos da qualidade da água subterrânea do Curtume 2.

Table 2 - Descriptive statistics of physical chemical, metallic and non-metallic variables of groundwater quality in tannery 2

\begin{tabular}{c|c|c|c|c|c|c|c}
\hline Parâmetros & Unidades & $\begin{array}{c}\text { Número de } \\
\text { Amostras }\end{array}$ & Média & $\begin{array}{c}\text { Desvio } \\
\text { Padrão }\end{array}$ & Mediana & Máximo & Mínimo \\
\hline Temperatura & ${ }^{\circ} \mathrm{C}$ & 29 & 29,1 & 1,19 & 29,1 & 31,5 & 26,6 \\
\hline $\mathrm{pH}$ & & 29 & 6,6 & 0,9 & 6,8 & 7,75 & 3,23 \\
\hline Alcalinidade & $\mathrm{mg} / \mathrm{L}$ & 23 & 224,1 & 467,4 & 79 & 1801 & 9 \\
\hline C.E. & $\mu \mathrm{S} / \mathrm{cm}$ & 29 & 2015 & 3365 & 444 & 13840 & 50 \\
\hline STD & $\mathrm{mg} / \mathrm{L}$ & 26 & 1246,1 & 2153 & 284 & 8996 & 38,67 \\
\hline Turbidez & $\mathrm{NTU}$ & 23 & 85,0 & 175,2 & 31 & 832 & 0,1 \\
\hline Nitrito & $\mathrm{mg} / \mathrm{L}$ & 27 & 0,026 & 0,04 & 0,007 & 0,19 & 0,005 \\
\hline Nitrato & $\mathrm{mg} / \mathrm{L}$ & 22 & 0,161 & 0,3 & 0,07 & 1,63 & 0,02 \\
\hline Amônia & $\mathrm{mg} / \mathrm{L}$ & 26 & 2,4 & 3,0 & 0,44 & 8,5 & 0,018 \\
\hline Fósforo & $\mathrm{mg} / \mathrm{L}$ & 23 & 0,32 & 0,42 & 0,14 & 1,87 & 0,05 \\
\hline Cloreto & $\mathrm{mg} / \mathrm{L}$ & 21 & 495,6 & 824 & 30,9 & 3183 & 1 \\
\hline Sulfato & $\mathrm{mg} / \mathrm{L}$ & 23 & 5,28 & 11,56 & 1,5 & 56 & 0,1 \\
\hline Cromo & $\mathrm{mg} / \mathrm{L}$ & 26 & 0,2 & 0 & 0,2 & 0,2 & 0,2 \\
\hline Cobre & $\mathrm{mg} / \mathrm{L}$ & 26 & 0,024 & 0,01 & 0,02 & 0,05 & 0,02 \\
\hline Chumbo & $\mathrm{mg} / \mathrm{L}$ & 26 & 0,5 & 0 & 0,5 & 0,5 & 0,5 \\
\hline Ferro & $\mathrm{mg} / \mathrm{L}$ & 26 & 0,94 & 1,65 & 0,28 & 7,67 & 0,2 \\
\hline Zinco & $\mathrm{mg} / \mathrm{L}$ & 26 & 0,078 & 0,073 & 0,05 & 0,39 & 0,05 \\
\hline Cadmio & $\mathrm{mg} / \mathrm{L}$ & 26 & 0,013 & 0,006 & 0,01 & 0,03 & 0,01 \\
\hline Manganês & $\mathrm{mg} / \mathrm{L}$ & 26 & 0,38 & 0,8 & 0,1 & 4,12 & 0,1 \\
\hline & & & & & & &
\end{tabular}

O nível da água nos poços de monitoramento do curtume 1 variou de 0,65 a $7,12 \mathrm{~m}$ (média de $3,4 \mathrm{~m}$ ) e do curtume 2 de 0,11 a $8,6 \mathrm{~m}$ (média 3,0 $\mathrm{m})$. Estes valores mostram águas subterrâneas rasas, típicas de aquíífero freático.

A temperatura da água na boca dos poços de monitoramento no curtume 1 variou de 26,1 a
$31,5{ }^{\circ} \mathrm{C}$ (média de $28,8{ }^{\circ} \mathrm{C}$ ) e no curtume 2 variou de 26,6 a $31,5^{\circ} \mathrm{C}$ (média de $29,2{ }^{\circ} \mathrm{C}$ ).

Os valores de $\mathrm{pH}$ das amostras dos poços de monitoramento do curtume 1 variaram de 4,20 a 6,83 (média 5,4) e do curtume 2 de 3,23 a 7,75 (média 6,2). Estes valores mostram tendência de $\mathrm{pH}$ neutro a relativamente ácido (Figura 3 ). 
No curtume 1, a comparação estatística empregando o método de Kruskal-Wallis mostrou diferenças estatisticamente significativas $(\mathrm{p}<0,05)$ entre o poço de background $\mathrm{e}$ os demais, indicando influência do curtume na acidez da água. $\mathrm{O}$ pH do poço de background foi inferior aos demais indicando que as substâncias alcalinas usadas no processo de curtimento estão sendo lixiviadas.

Por outro lado, no curtume 2, a comparação estatística empregando o método de KruskalWallis não mostrou diferenças estatisticamente significativas.

A alcalinidade das águas subterrâneas do curtume 1 variou de 0 a $2.830 \mathrm{mg} / \mathrm{L}$ (média de $117 \mathrm{mg} / \mathrm{L}$ ) e no curtume 2 variou de 9 a 1.801 $\mathrm{mg} / \mathrm{L}$ (média de $224 \mathrm{mg} / \mathrm{L}$ ).

Com exceção de uma coleta no PM1 do curtume 1 e de duas coletas no PM1 do curtume 2 , os demais valores de alcalinidade foram baixos e semelhantes, não possibilitando concluir sobre a influência da disposição dos resíduos dos curtumes sobre esta variável (Figura 4).

Observou-se que os valores de condutividade elétrica do curtume 1, para cada poço de monitoramento, não foram homogêneos nas diversas épocas do ano, com tendência de aumento no período chuvoso. Observou-se também, que os poços de monitoramento PM1 e PM3 destacaram-se dos demais por apresentar altas condutividades elétricas, normalmente acima dos valores do poço de background (PM0), indicando que os rejeitos do curtume 1 elevaram a condutividade elétrica das águas subterrâneas nestes poços. O PM1 apresentou os maiores valores de condutividade elétrica.

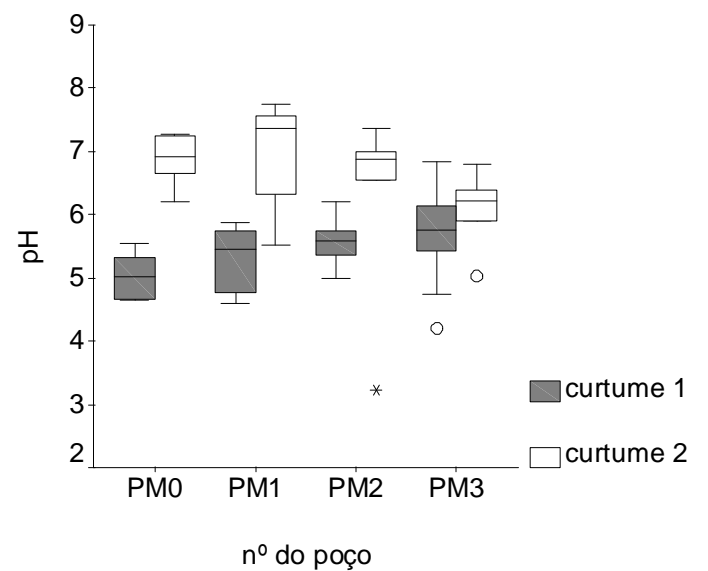

Figura 3 - Boxplot do pH dos poços de monitoramento dos curtumes 1 e 2.

Figure 3 - Boxplot of $p H$ of the monitoring wells in tanneries 1 and 2.

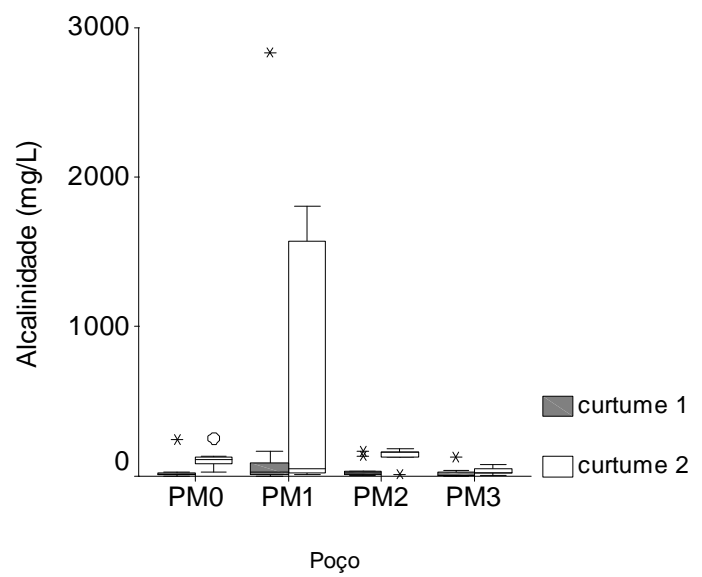

Figura 4 - Boxplot da alcalinidade das águas subterrâneas dos poços de monitoramento dos curtumes 1 e 2 .

Figure 4 - Boxplot of groundwater alkalinity of the monitoring wells in tanneries 1 and 2.

A condutividade elétrica das amostras de água do curtume 1 apresentou valores entre 27,7 e $3.340 \mu \mathrm{S} / \mathrm{cm}$ (média de $534 \mu \mathrm{S} / \mathrm{cm}$ ) e no curtume 2 valores entre 50 e $13.840 \mu \mathrm{S} / \mathrm{cm}$ (média de $2.015 \mu \mathrm{S} / \mathrm{cm}$ ) (Figura 5).

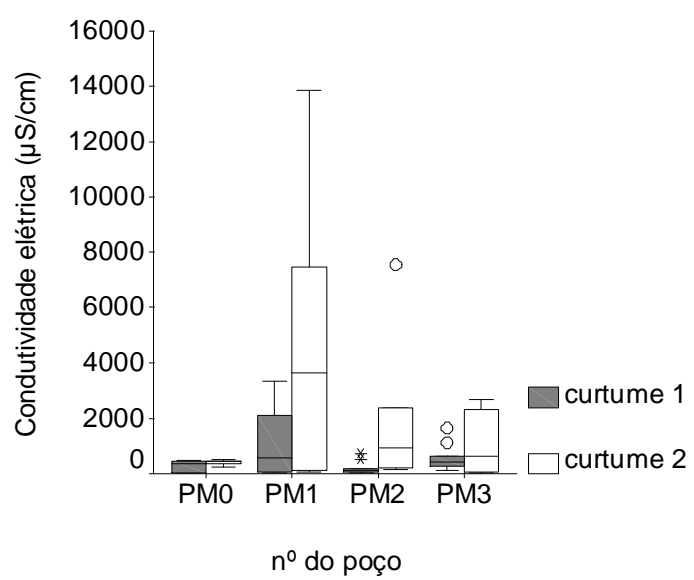

Figura 5 - Boxplot da condutividade elétrica dos poços de monitoramento dos curtumes 1 e 2 .

Figure 5 - Boxplot of electrical conductivity of the monitoring wells in tanneries 1 and 2 .

De forma análoga ao curtume 1, a condutividade elétrica das águas dos poços de monitoramento do curtume 2 não foram homogêneos nas diversas épocas do ano. Notouse ainda, que em diversas datas, os poços de monitoramento PM1, PM2 e PM3 apresentaram valores de condutividade elétrica acima dos valores de background, indicando que os rejeitos do curtume 2 também contribuíram para elevar a condutividade elétrica das águas subterrâneas. $\mathrm{O}$ PM1 apresentou os maiores valores de condutividade elétrica. 
A concentração de Sólidos Totais Dissolvidos foi calculada diretamente a partir dos valores de condutividade elétrica, segundo Mathess (1982). O fato dos sólidos totais dissolvidos terem sido calculados diretamente a partir da condutividade elétrica pressupõe que esses sólidos sejam constituídos basicamente por íons, que são os responsáveis pela condução de eletricidade no meio aquoso. Portanto, é de se esperar que exista uma boa correlação entre a concentração total de íons e os valores obtidos de condutividade elétrica.

A concentração de STD no curtume 1 variou de 18 a $2.171 \mathrm{mg} / \mathrm{L}$ (média de $350 \mathrm{mg} / \mathrm{L}$ ) e no curtume 2 variou de 38,6 a $8.996 \mathrm{mg} / \mathrm{L}$ (média de $1.246 \mathrm{mg} / \mathrm{L})$.

Acompanhando as variações da condutividade elétrica, os teores de STD não foram homogêneos durante o período de estudo nos dois curtumes, e os valores dos poços PM1, PM2 e PM3 foram, de uma forma geral, superiores aos de background, indicando que os resíduos de curtume alteraram os teores de STD nas águas subterrâneas nestes curtumes.

Os valores de turbidez no curtume 1 variaram de 1,4 a 1.485 NTU (média de 214 NTU) e no curtume 2 variaram de 0,1 a 832 NTU (média de 85 NTU).

$\mathrm{O}$ curtume 1 mostrou uma grande heterogeneidade de valores de turbidez. Notou-se que mesmo o poço de background apresentou valores elevados, não permitindo concluir com certeza que os valores de turbidez estão relacionados ao curtume, provavelmente estes teores estão relacionados a poços de monitoramento com problemas construtivos. Os valores mais elevados de turbidez, para os dois curtumes, ocorreram no período de maio a setembro, ou seja, no período de seca (Figura 6).

A concentração de nitrito no curtume 1 variou de 0,005 a $0,186 \mathrm{mg} / \mathrm{L}$ (média de 0,028 ) e no curtume 2 variou de 0,005 a $0,196 \mathrm{mg} / \mathrm{L}$ (média de $0,02 \mathrm{mg} / \mathrm{L}$ ), enquanto a concentração de nitrato no curtume 1 variou de 0,02 a 1,44 $\mathrm{mg} / \mathrm{L}$ (média de $0,14 \mathrm{mg} / \mathrm{L}$ ) e no curtume 2 variou de 0,02 a $1,63 \mathrm{mg} / \mathrm{L}$ (média de $0,16 \mathrm{mg} / \mathrm{L})$.

No curtume 1, das 36 análises realizadas, 21 apresentaram concentração de nitrito abaixo do limite de detecção do método empregado $(<0,005 \mathrm{mg} / \mathrm{L})$ e 27 apresentaram concentração de nitrato abaixo do limite de detecção do método empregado $(<0,02 \mathrm{mg} / \mathrm{L})$. As concentrações de nitrito e nitrato dos poços PM1, PM2 e PM3 não apresentaram diferenças significativas com os valores de background (PM0), indicando que os rejeitos de curtume não estão interferindo nos teores destes íons nas águas subterrâneas deste curtume (Figura 7).

No curtume 2, observou-se que das 27 análises realizadas, 13 estavam com concentração de nitrito abaixo do limite de detecção do método empregado. A mesma tendência de teores de nitrito e nitrato nos poços PM1, PM2 e PM2 foram observados neste caso, indicando também que os rejeitos de curtume não estão elevando os teores destes íons nas águas subterrâneas do curtume 2 (Figura 7).
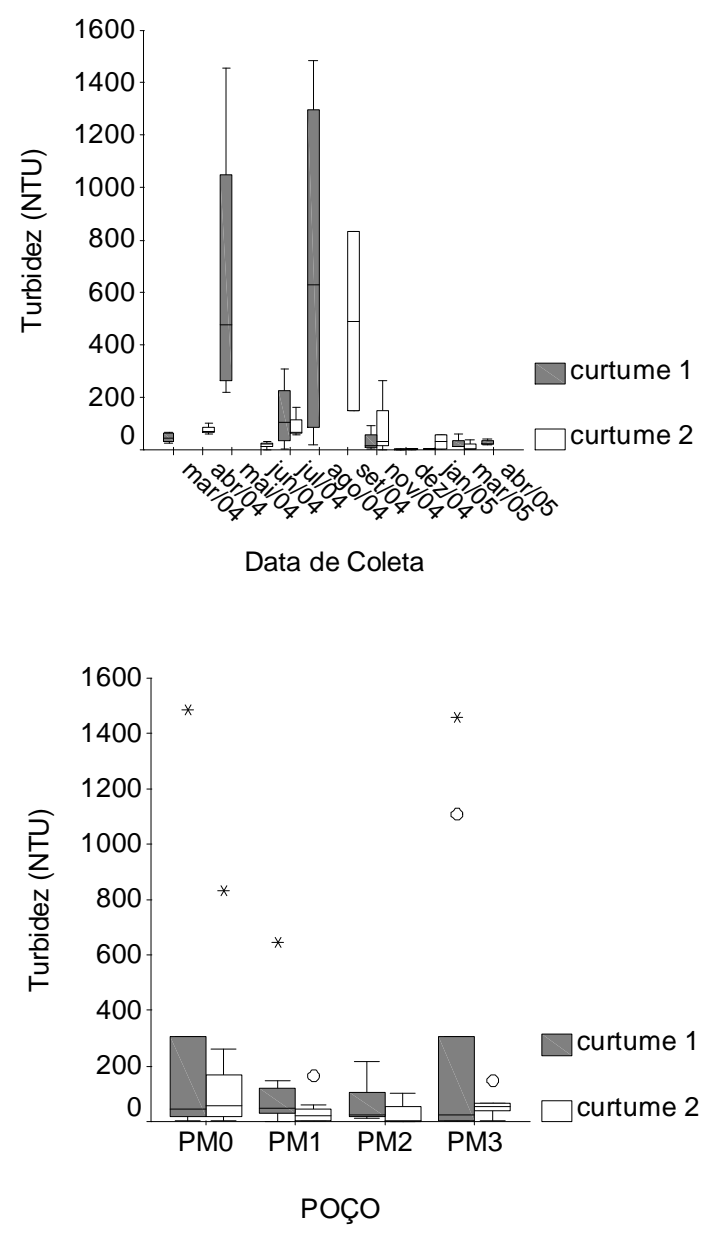

Figura 6 - Boxplot da turbidez das águas dos poços de monitoramento dos curtumes 1 e 2 , por data de coleta (A) e por poço (B).

Figure 6-Boxplot of turbidity of the monitoring wells in tanneries 1 and 2 , at different sampling date $(A)$ and at different monitoring wells $(B)$. 

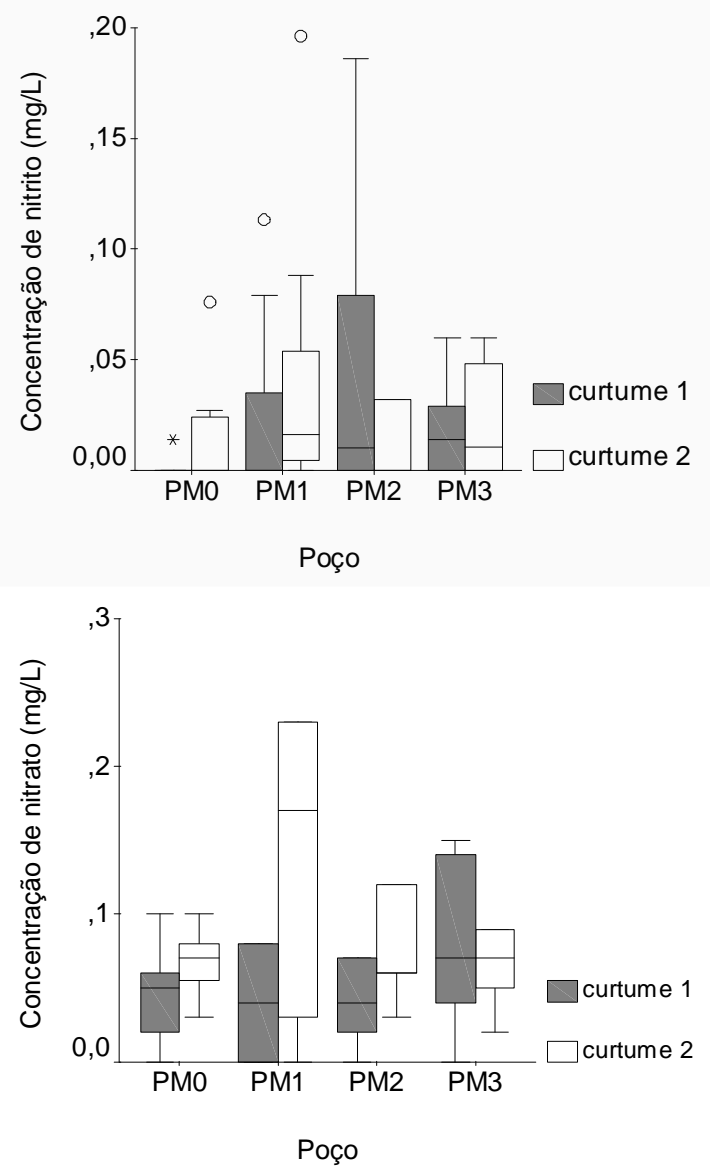

Figura 7 - Boxplot das concentrações de nitrito e nitrato nas águas subterrâneas dos poços de monitoramento curtumes 1 e 2 .

Figure 7 - Boxplot of nitrite and nitrate concentrations of the monitoring wells in tanneries 1 and 2.

A concentração da amônia no curtume 1 variou de 0,01 a $10,15 \mathrm{mg} / \mathrm{L}$ (média de $1,0 \mathrm{mg} / \mathrm{L}$ ) e no curtume 2 variou de 0,018 a $8,5 \mathrm{mg} / \mathrm{L}$ (média de 2,4 mg/L).

As concentrações de amônia nos poços de monitoramento dos dois curtumes e nos respectivos poços de background, não apresentaram diferenças estatisticamente significativas, indicando que a disposição dos rejeitos não alterou as concentrações de amônia nas águas subterrâneas (Figura 8).

As concentrações de cloreto do curtume 1 variaram de 1,5 a $1.530 \mathrm{mg} / \mathrm{L}$ (média de 210 $\mathrm{mg} / \mathrm{L}$ ) e do curtume 2 variaram de 1 a 3.182 $\mathrm{mg} / \mathrm{L}$ (média de 495,6 mg/L).

No curtume 1, não se observou diferenças estatisticamente significativas entre as concentrações de cloreto dos poços de monitoramento e o de background; entretanto, em diversas datas estas concentrações no PM1, PM2 e o PM3 foram superiores aos valores do poço de background, indicando uma provável influência dos resíduos de curtume elevando os teores deste íon nas águas subterrâneas (Figura $8)$.

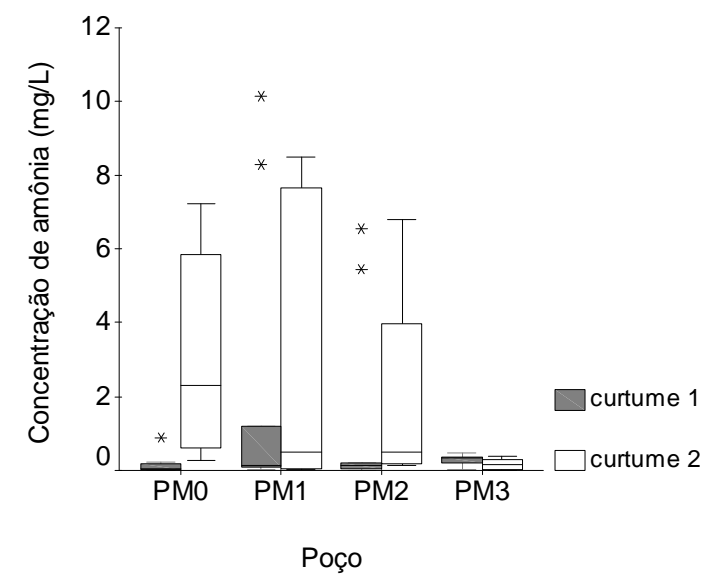

Figura 8 - Boxplot das concentrações de amônia nos poços de monitoramento dos curtumes 1 e 2 .

Figure 8 - Boxplot of ammonium concentrations of the monitoring wells in tanneries 1 and 2.

Já no curtume 2, a comparação estatística mostrou que houveram diferenças significativas entre os poços PM1, PM2, PM3 e o poço de background (PM0), indicando a alteração na concentração de cloreto pela presença dos resíduos deste curtume (Figura 9).

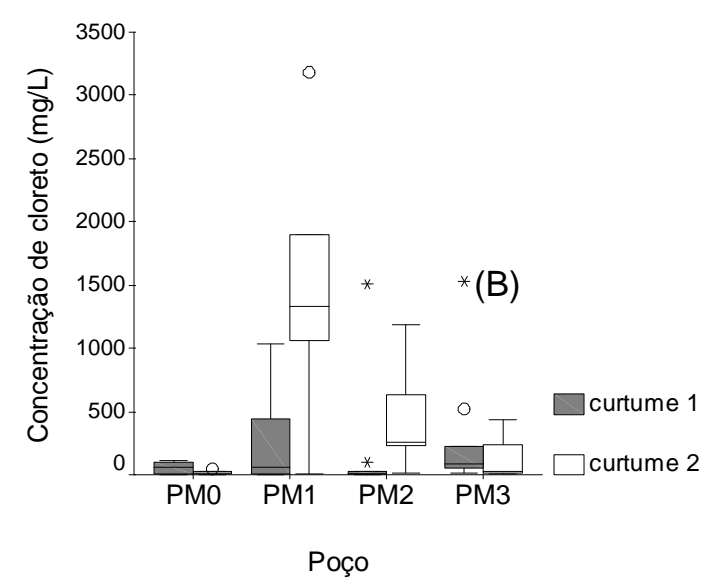

Figura 9 - Boxplot das concentrações de cloreto nas águas subterrâneas dos poços de monitoramento curtumes 1 e 2 .

Figure 9 - Boxplot of chloride concentrations of the monitoring wells in tanneries 1 and 2.

A concentração do fósforo no curtume 1 variou de 0,02 a $0,99 \mathrm{mg} / \mathrm{L}$ (média de $0,2 \mathrm{mg} / \mathrm{L}$ ) e no curtume 2 variou de 0,05 a $1,9 \mathrm{mg} / \mathrm{L}$ (média de $0,32 \mathrm{mg} / \mathrm{L}$ ).

Não se observaram diferenças estatisticamente significativas entre as 
concentrações de fósforo total nas águas dos poços de monitoramento e os poços de background nos dois curtumes, indicando que não houve influência da disposição dos rejeitos dos curtumes sobre esta variável (Figura 10).

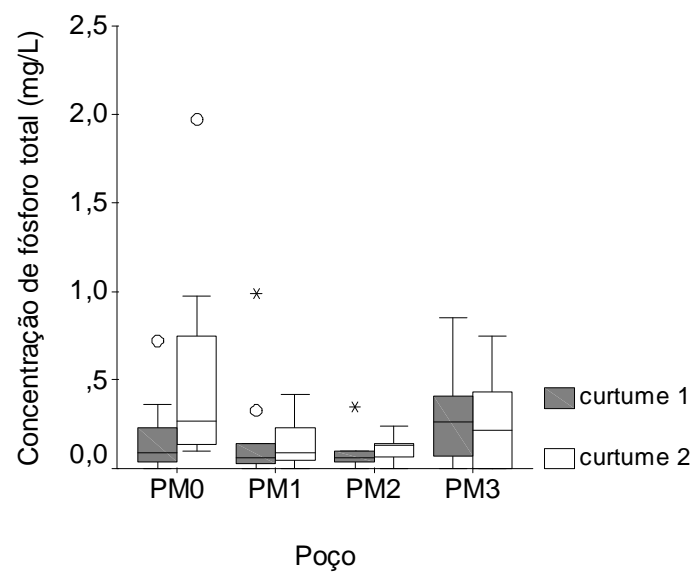

Figura 10 - Boxplot da concentração de fósforo total nos poços de monitoramento dos curtumes $1 \mathrm{e}$ 2.

Figure 10 - Boxplot of total phosphorus concentrtion of the monitoring wells in tanneries 1 and 2.

A concentração do sulfato no curtume 1 variou de 0,1 a 40,6 mg/L (média de 3,9 mg/L) e no curtume 2 variou de 0,1 a $56 \mathrm{mg} / \mathrm{L}$ (média de $5,3 \mathrm{mg} / \mathrm{L})$.

No curtume 1, das 36 análises realizadas 18 estavam abaixo do limite de detecção do método empregado $(<0,10 \mathrm{mg} / \mathrm{L})$.

Nos dois curtumes, os teores de sulfato mostraram-se baixos e homogêneos por poço de monitoramento nas diversas épocas de amostragem, não apresentando diferenças estatisticamente significativas, entre os poços de monitoramento e os respectivos poços de background, indicando que os resíduos de curtume não alteraram os teores desta variável (Figura 11).

A concentração do cromo no curtume 1 variou de 0,2 a $1,92 \mathrm{mg} / \mathrm{L}$ (média de $0,28 \mathrm{mg} / \mathrm{L}$ ) e no curtume 2 todas as concentrações estavam abaixo do limite de detecção do método empregado.

No curtume 1, das 40 análises realizadas, 36 apresentaram concentração abaixo do limite de detecção do método empregado $(<0,20 \mathrm{mg} / \mathrm{L})$. O poço de monitoramento PM2, em uma data e o PM3, em três datas de coleta, apresentaram teores de cromo acima dos de background, indicando que nestes dias as águas subterrâneas foram alteradas pelos resíduos do curtume 1 .

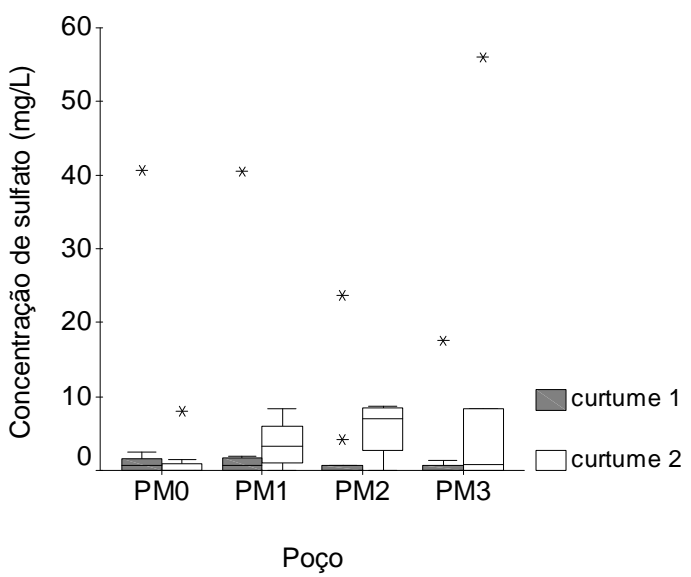

Figura 11 - Boxplot das concentrações de sulfato nos poços de monitoramento dos curtumes 1 e 2. Figure 11 - Boxplot of sulfate concentrations of the monitoring wells in tanneries 1 and 2.

Já no curtume 2, foram realizadas 26 análises de cromo e todas estavam abaixo do limite de detecção do método empregado. Concluiu-se que o cromo não alterou a qualidade das águas subterrâneas do curtume 2 .

A concentração do cobre no curtume 1 variou de 0,02 a 0,09 $\mathrm{mg} / \mathrm{L}$ (média de 0,029 $\mathrm{mg} / \mathrm{L}$ ) e no curtume 2 variou de 0,02 a $0,05 \mathrm{mg} / \mathrm{L}$ (média de 0,02 mg/L).

No curtume 1, das 40 análises realizadas, 35 apresentaram concentração abaixo do limite de detecção do método empregado $(0,02 \mathrm{mg} / \mathrm{L})$ e no curtume 2, das 26 amostras analisadas, detectouse o cobre em concentrações acima do limite de detecção do método somente em sete amostras. Não se verificou alteração significativa na concentração de cobre nas águas subterrâneas dos dois curtumes devido a disposição dos resíduos.

A concentração do chumbo no curtume 1 variou de 0,50 a $0,61 \mathrm{mg} / \mathrm{L}$ (média de $0,50 \mathrm{mg} / \mathrm{L}$ ) e no curtume 2 , todas as concentrações estavam abaixo do limite de detecção do método empregado $(0,50 \mathrm{mg} / \mathrm{L})$.

No curtume 1, das 40 análises realizadas, 37 apresentaram concentração abaixo do limite de detecção do método empregado e no curtume 2 foram realizadas 26 análises de chumbo e todas estavam abaixo do limite de detecção. Da mesma forma que o cobre, a disposição final dos rejeitos dos dois curtumes não alterou a concentração de chumbo nas águas subterrâneas.

De maneira geral, grande parte das águas subterrâneas da região de Cuiabá apresenta concentração elevada de ferro. Este fator se deve ao solo laterítico típico do Grupo Cuiabá e da ocorrência de piritas disseminadas tanto nos 
filitos como nos metadiamictitos (MIGLIORINI, 1999).

A concentração de ferro no curtume 1 variou de 0,2 a $14,43 \mathrm{mg} / \mathrm{L}$ (média de $1,6 \mathrm{mg} / \mathrm{L}$ ) e no curtume 2 que variaram de 0,20 a 7,67 mg/L (média de $0,94 \mathrm{mg} / \mathrm{L}$ ).

No curtume 1, das 40 análises realizadas, 16 apresentaram concentração abaixo do limite de detecção do método empregado $(0,20 \mathrm{mg} / \mathrm{L})$ e no curtume 2, observou-se que 6 análises estavam abaixo do limite de detecção do método empregado.

As concentrações de ferro nos dois curtumes mostraram-se bastante heterogêneas ao longo do período do estudo e não se observaram diferenças estatisticamente significativas entre os resultados dos poços de monitoramento e os de background (Figura 12). Concluiu-se, deste modo, que esta grande heterogeneidade da concentração de ferro deve-se à formação geológica e não aos resíduos dos curtumes.

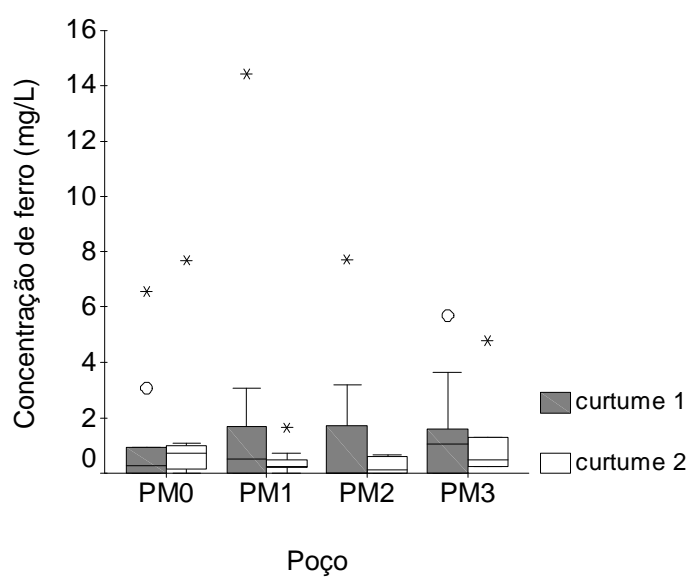

Figura 12 - Boxplot das concentrações de ferro nos poços de monitoramento dos curtumes 1 e 2 . Figure 12 - Boxplot of iron concentrations of the monitoring wells in tanneries 1 and 2.

A concentração de zinco no curtume 1 variou de 0,05 a $0,38 \mathrm{mg} / \mathrm{L}$ (média de $0,09 \mathrm{mg} / \mathrm{L}$ ) e no curtume 2 variou de 0,05 a $0,39 \mathrm{mg} / \mathrm{L}$ (média de $0,08 \mathrm{mg} / \mathrm{L})$.

Das 40 análises realizadas no curtume 1,19 apresentaram concentração abaixo do limite de detecção do método empregado $(0,05 \mathrm{mg} / \mathrm{L})$ e no curtume 2, 16 encontravam-se abaixo do limite de detecção.

Não se observou diferenças estatisticamente significativas entre os poços de monitoramento e os de background, indicando que os resíduos de curtume não alteraram a qualidade das águas subterrâneas por este metal (Figura 13).

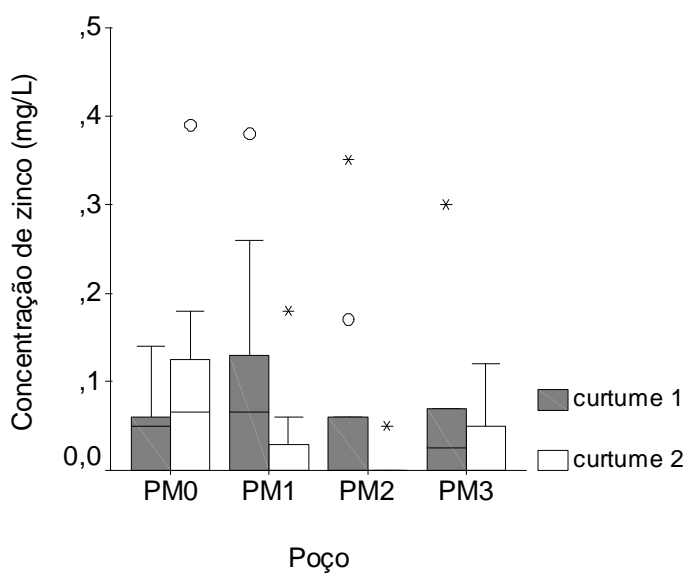

Figura 13 - Boxplot das concentrações de zinco nos poços de monitoramento dos curtumes 1 e 2.

Figure 13 - Boxplot of zinc concentrations of the monitoring wells in tanneries 1 and 2.

A concentração do cádmio no curtume 1 variou de 0,10 a $0,03 \mathrm{mg} / \mathrm{L}$ (média de $0,01 \mathrm{mg} / \mathrm{L}$ ) e no curtume 2 variou de 0,01 a $0,03 \mathrm{mg} / \mathrm{L}$ (média de $0,013 \mathrm{mg} / \mathrm{L}$ ).

No curtume 1, das 40 análises realizadas, 36 apresentaram concentração abaixo do limite de detecção do método empregado $(0,01 \mathrm{mg} / \mathrm{L})$ e no curtume 2 foram realizadas 26 análises de cádmio, sendo que 18 análises apresentaram concentração abaixo deste limite. Não se observaram diferenças estatisticamente significativas entre os poços de monitoramento e o de background e não se verificou alteração da qualidade das águas subterrâneas por este metal, nos dois curtumes.

A concentração de manganês no curtume 1 variou de 0,10 a $4,62 \mathrm{mg} / \mathrm{L}$ (média de $0,73 \mathrm{mg} / \mathrm{L}$ ) e no curtume 2 variou de 0,10 a $4,12 \mathrm{mg} / \mathrm{L}$ (média de $0,38 \mathrm{mg} / \mathrm{L}$ ).

Não se observaram diferenças estatisticamente significativas entre as concentrações de manganês nos poços de monitoramento e os de background nos dois curtumes, havendo grande heterogeneidade nestas concentrações ao longo do período do estudo. Concentrações de manganês mais elevadas no poço de background sugere que a ocorrência deste metal na água subterrânea seja decorrente da formação geológica e não dos rejeitos do curtume. 


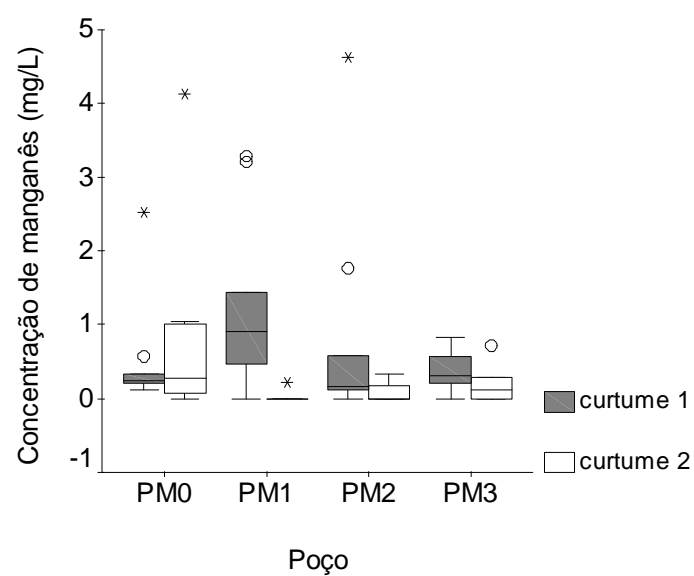

Figura 14 - Boxplot das concentrações de manganês nos poços de monitoramento dos curtumes 1 e 2 .

Figure 14-Boxplot of manganese concentrations of the monitoring wells in tanneries 1 and 2.

\section{CONCLUSÕES}

As análises físico-químicas dos elementos metálicos e não metálicos das águas subterrâneas, nas áreas de disposição final dos resíduos gerados pelos curtumes, permitiram as seguintes conclusões:

1- A presença dos resíduos gerados pelo curtume 1, contribuiu para elevar os teores de cromo, $\mathrm{pH}$, condutividade elétrica e, portanto, também sólidos totais dissolvidos;

2- A presença dos resíduos gerados pelo curtume 2, contribuiu para elevar os teores de cloreto, condutividade elétrica e, por conseqüência, de sólidos totais dissolvidos.

3- Embora os dois curtumes estejam em funcionamento por períodos diferentes (curtume 1 foi implantado no ano 2000 e o curtume 2 em 1986) e usando métodos diferentes de disposição dos rejeitos, não se observou diferenças significativas nas alterações da qualidade das águas subterrâneas nos dois locais. 


\section{REFERÊNCIAS}

CLAAS, I.C.; MAIA, R.A.M. Manual Básico de Resíduos Industriais de Curtume. Porto Alegre: SENAI/RS, 1994.

COSTA, R.V.; MIGLIORINI, R.B. Resíduos Sólidos de Curtume podem Contaminar as Águas Subterrâneas. Região de Cuiabá - MT. In: Encontro de Iniciação Científica, 2005, Cuiabá. Anais do XIII Encontro de Iniciação Científica. Cuiabá: Edufmt, 2005. V. 1. p. 76-76.

CUNHA, L.F.J. da. Mapeamento da Pluma de Contaminação em Depósitos de Resíduos de Couro, através de Métodos Geofísicos - Dois Casos em Mato Grosso. Cuiabá, 2005. Dissertação (Mestrado em Geofísica). Instituto de Ciências Exatas e da Terra - UFMT.

FACHIN, S.J.S.; HUBER F.; SHIRAIWA, S.; BORGES, W.R. e MIGLIORINI, R.B. Aplicação de Métodos Geofísicos para Identificar Áreas Contaminadas por Resíduos de um Curtume. Revista Brasileira de Geofísica, 24(1): p. 129 - 138, 2006.

GOOGLE. Google Earth System Online. Disponível em: <www.earth.google.com>.

Acessado em 10/10/2007.

JOST, P. T. Semana de Debates Sobre Tratamento de Efluentes de Curtume. Estância Velha / RS: 1984.

LANNES, S. Avaliação da Qualidade da Água Subterrânea na Área de Disposição do Lodo Proveniente do Curtume Berto - Várzea Grande / MT. Dissertação de Mestrado. Instituto de Ciências Exatas e da Terra, 2002. Universidade Federal de Mato Grosso.

LUZ, J.S.; OLIVEIRA, A.M.; SOUZA, J.O.; MOTTA, J.F.M.; TANNO, L.C.; CARMO, L.S.; SOUZA, N.B. Projeto Coxipó. Relatório Final. DNPM/CPRM, v. 1., Goiânia: 1980, 136p.

MATTHESS, G. The Properties of Groundwater. New York: John Wiley \& Sons. 1982.

MIGLIORINI, R.B. Hidrogeologia em Meio Urbano. Região de Cuiabá e Várzea Grande - MT. Tese de Doutoramento. Instituto de Geociências, 1999. Universidade de São Paulo.
MONDAL, N.C.; SAXENA, V. and SINGN, V.S. Assessment of Groundwater Pollution due to Tannery Industries In and Aurond Dindigul, Tamilnadu, India. Environmental Geology, 2005. 48: 149-157.

RIBEIRO NETO, J.I. Inovações Tecnológicas em Indústria de Curtimento. Monografia de Curso de Especialização. Instituto de Biociências, 2002. Universidade Federal de Mato Grosso.

SELBACH, P.A. Descarte e Biodegradação de Lodo de Curtume no Solo. In: Revista do Couro. 1991, p. 51-52.

SISTEMA IBGE DE RECUPERAÇÃO AUTOMÁTICA. Relatório/Abril de 2006 a março de 2007. MT-4.858.878. disponível em: www.sidra.ibge.gov.br/bda/tabela/protabe.asp?z=\&0= 21\&j=p; acessado em 2007.

\section{STANDARD METHODS FOR THE} EXAMINATION OF WATER AND WASTEWATER. APHA, AWWA, WPCF, $16^{\text {th }}$ ed., Port City Press: Baltimore, 1998, 373p.

VOGADO, M.W.; MIGLIORINI, R.B. Estudo Hidrogeológico em Áreas de Curtume. Região de Várzea Grande. In: XIII Encontro de Iniciação Científica, 2005, Cuiabá. Anais do XIII Encontro de Iniciação Científica. Cuiabá: Edufmt, 2005. v.1. p.7171.

VOGADO, M.W.; MIGLIORINI, R.B. Contaminação de Águas Subterrâneas em Áreas de Disposição Final de Resíduos de Curtume. In: XLIII Congresso Brasileiro de Geologia, 2006, Aracaju. Geociências e as Sociedades do Futuro, 2006.p.238238.

ZAHID, A.; BALKE, K.D; FLEGR, M and HASSAN, M.Q. Evaluation of Aquifer Environment Under Hazaribagh Leather Processing Zone of Dhaka City. Environmental Geology, 2006, 50:495-504.

\section{AGRADECIMENTOS}

Os autores agradecem à Fundação de Amparo à Pesquisa do Estado de Mato Grosso - FAPEMAT pelo apoio financeiro (processo $\mathrm{n}^{\circ}$ 3.2.2.240/08-2002. E), sem o qual este trabalho não se realizaria. 